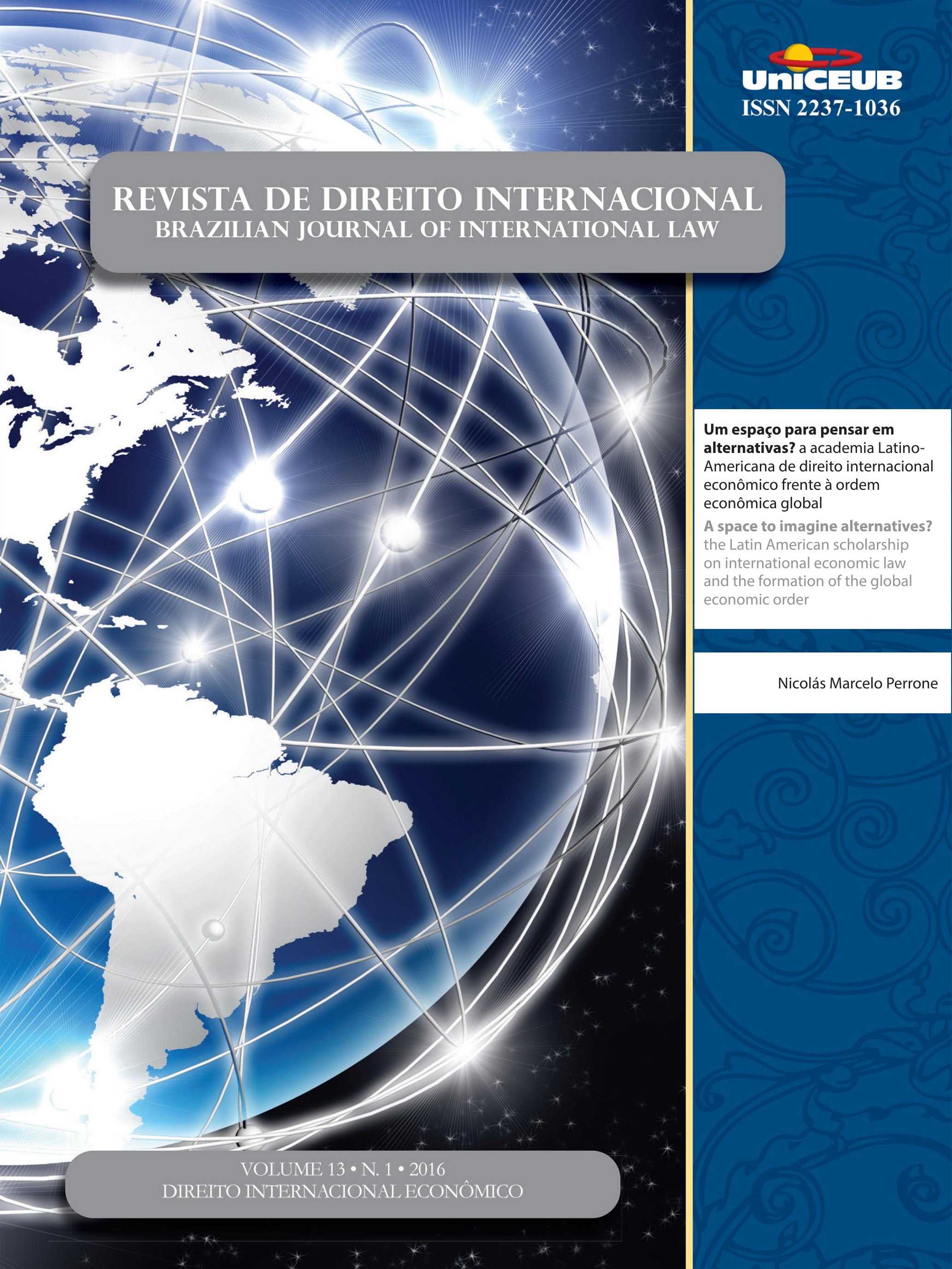




\section{Sumário}

Dossiê Temático: Direito Internacional Econômico.........................................................1

EDITORIAL:

Resultados da III Conferência Bienal da Red DEI ................................................. 3

Michelle Ratton Sanchez-Badin (em nome da Diretoria da Red DEI), Fabio Costa Morosini e Lucas da Silva Tasquetto (em nome dos organizadores da III Conferência da Red DEI)

Direito Internacional Econômico no Brasil: QUem Somos E o QUE faZemos? EvidênCIas EMPÍRICAS DE 1994 A 2014

Michelle Ratton Sanchez Badin, Fabio Costa Morosini e Inaê Siqueira de Oliveira

UM ESPAÇO PARA PENSAR EM ALTERNATIVAS? A ACADEMIA LATINO-AMERICANA DE DIREITO INTERNACIONAL ECONÔMICO FRENTE À ORDEM ECONÔMICA GLOBAL

Nicolás Marcelo Perrone

Grupo de alto Nível Brasil - Urugua (GAN): um Novo paradigma para a INTEgraÇão PRODUTIVA NO MERCOSUL

Alebe Linhares Mesquita e Vivian Daniele Rocha Gabriel

O COMÉRCIO de SERVIÇOS ENTRE Brasil E URUGUAI: LiberalizaÇÃo, DESAFIOS E PERSPECTIVAS DO SETOR DE TECNOLOGIA DA INFORMAÇÃO E COMUNICAÇÃO (TIC) E SOFTWARES

Vivian Daniele Rocha Gabriel e Alebe Linhares Mesquita

Core Labor Standards No Regime de PREFERÊNCIAS TARIFÁrias No MERCOSUL: A NeCESSIDADE DE HUMANIZAÇÃO DO COMÉRCIO INTERNACIONAL

Martinho Martins Botelho e Marco Antônio César Villatore

ACordo TRIMS: FleXibilizaÇão ou Não? Política de CONTEÚdo loCal, PROCESSO PROdUTIVO BÁSICO (PPB) E OS DESAFIOS PARA A INDÚSTRIA BRASILEIRA E A INTEGRAÇÃo LATINO-AMERICANA 100

Natália Figueiredo 
ESTUDIOS DE CASO DE RECHAZOS EN FRONTERA DE EXPORTACIONES ALIMENTARIAS LATINOAMERICANAS POR MOTIVOS RELACIONADOS CON MEDIDAS TÉCNICAS NO ARANCELARIAS.

Sofía Boza, Juan Rozas e Rodolfo Rivers

América do Sul em face dos tratados bilaterais de inVESTimento: RUMO aO RETORNo do EsTADO NA SOLUÇão DE CONTROvÉRSIAS? 133 Magdalena Bas

FutURo DE LOS SISTEMAS NACIONALES DE CIENCIA TECNOLOGÍA E INNOVACIÓN EN LA AGENDA ECONÓMICA DE AMÉRICA LATINA: DEFINIENDO CAMBIOS REGULATORIOS O PROTEGIENDO INVERSIONES 146

Rodrigo Corredor

EL PAPEL DE LAS INSTITUCIONES DE CONTROL FINANCIERO SOBRE LOS DERECHOS HUMANOS EN EL CONTEXTO LATINOAMERICANO 157 Jose Miguel Camacho Castro

CONVERGENCIA REgUlATORIA EN LA ALIANZA DEL PACÍFICO: UN CAPÍTULO INCONCLUSO 170 Rodrigo Polanco Lazo

O CONSTITUCIONALISMO E A COMUNITARIZAÇÃO NO DIREITO INTERNACIONAL: POSSIBILIDADES PARA O COMÉRCIO INTERNACIONAL?

Camilla Capucio

ESCASSEZ HÍDRICA E DIREITO INTERNACIONAL ECONÔMICO: O BRASIL COMO PROTAGONISTA NA TRANSFERÊNCIA DE ÁGUA PARA REGIÕES ÁRIDAS

Douglas de Castro

A Segurança energética como base para maior integração na América Do Sul: à espera DE UM TRATADO MULTILATERAL

Matheus Bassani

Outros Artigos. 246

As PRÁtICAS RESTRITIVAS DA CONCORRÊNCIA NO MERCADO DE CONTRATAÇÃo PÚBLICA EUROPEU .. 248 Alice Rocha da Silva e Ruth M. P. Santos 
Do TRANSNACIONAL PARA O NACIONAL: IOSCO, O MERCADO DE VALORES MOBILIÁRIOS BRASILEIRO E ACCOUNTABILITY

Salem Nasser, Nora Rachman e Viviane Muller Prado

MigRaÇÃo de TRABALHADORES INTELECTUAIS BRASILEIROS PARA O MERCADO INTERNACIONAL: IDENTIFICAÇÃO DE ATOS DE ALICIAMENTO DE EMPREGADOS E MECANISMOS LEGAIS PARA IMPEDIR A APROPRIAÇÃo TECNOLÓGICA E CONCORRÊNCIA DESLEAL ..........................................285 José Carlos Vaz e Dias e João Marcelo Sant'Anna da Costa

THE EASIER WAY TO HAVE "BETTER LAW"? THE MOST-SIGNIFICANT-RELATIONSHIP DOCTRINE AS THE FALLBACK CONFLICT-OF-LAW RULE IN THE PEOPLE'S REPUBLIC OF CHINA

Chi Chung

REFLEXOS JURÍDiCOS DA GOVERNANÇA GLOBAL SUBNACIONAL: A PARADIPLOMACIA E O DIREITO INTERNACIONAL: DESAFIO OU ACOMODAÇÃO 320

Valéria Cristina Farias e Fernando Rei

Matrizes Políticas da JUSTiÇA PENAL INTERNACIONAL. 341 Francisco Rezek

RESPONSABILIDAD INTERNACIONAL DEL ESTADO FRENTE A LUCHA CONTRA LA DISCRIMINACIÓN RACIAL Y ÉTNICA EN ESPAÑA. 348

Edilney Tomé da Mata e Eduardo Biacchi Gomes Correio

The Peace Process in Sierra Leone: an analysis on marriages between culture and CRIME

Gustavo Bussmann Ferreira

Funcionalização e expansão do Direito Penal: o Direito Penal negocial ...............376 Antonio Henrique Graciano Suxberger e Dermeval Farias Gomes Filho

Proteção Internacional do Consumidor e Cooperação Interjurisdicional .396 Héctor Valverde Santana e Sophia Martini Vial

The land rights of indigenous and traditional peoples in Brazil and Australia.... 418 Márcia Dieguez Leuzinger e Kylie Lyngard 
The reception of European ideas in Latin America: the issue of the German sources in Tobias Barreto, A Prominent nineteenth CENTURy BraZilian legal scholar........439 Arnaldo Sampaio de Moraes Godoy

Normas Editoriais ..................................................................................... 461 


\title{
Um espaço para pensar em alternativas? a academia Latino-Americana de direito internacional econômico frente à ordem econômica global*
}

\author{
A space to imagine alternatives? the \\ Latin American scholarship on international \\ economic law and the formation of the global \\ economic order
}

Nicolás Marcelo Perrone **

\section{Resumo}

Este artigo tem por objetivo analisar o papel da academia latino-americana de direito internacional econômico frente à ordem econômica global. Grande parte dos problemas que hoje enfrentam os latino-americanos está ligada à globalização econômica. Condições de trabalho, acesso a medicamentos, uso de recursos naturais, entre outros, estão intimamente ligados à ordem econômica global. Em relação ao debate sobre esses problemas, não obstante, poucas vezes reconhece-se o papel fundamental que tem a academia de direito internacional econômico. Embora seja certo que o conhecimento articulado pela academia não é suficiente para explicar por que os Estados atuam de certa forma, talvez seja suficiente para entender por que não atuam de outra maneira. Nesse contexto, o argumento central deste artigo é que a academia de direito internacional econômico tem um papel-chave na manutenção e na reprodução da atual ordem econômica global. Ante essa premissa, a academia regional pode fazer mais pela América Latina que servir de apoio às necessidades estatais, tanto de assessoria como de defesa de seus interesses em controvérsias legais. Ao tomar consciência de seu papel constitutivo da ordem econômica global, a academia regional pode ser um meio fundamental para articular alternativas que permitam à América Latina e a sua população encontrar seu lugar na globalização.

Palavras-chave: Direito Internacional Econômico. América Latina. Globalização. Investimentos estrangeiros. Comércio Internacional.

\section{Abstract}

This article aims to analyse the role of the Latin American scholarship on international economic law in the formation of the global economic order. A large number of the problems that many Latin Americans face today relate to the global economy. Labour conditions, access to medicines, the use of natural resources, among others, are closely connected to the global economic order. In few instances, however, the debate on these 
problems recognises the fundamental role of the international economic law scholarship. Although the actual knowledge created by this scholarship does not explain why States behave in a certain way, it may serve to explain why they do not behave otherwise. This article argues that the scholarship on international economic law plays a crucial role in the creation and reproduction of the current global economic order. If this is correct, the regional scholarship can do more for Latin American than meeting the advisory and litigation needs of states. It can promote alternatives that can help the region and its people to find their place in the global economy.

Keywords: International Economic Law. Latin America. Globalisation. Foreign Investment. International Trade.

\section{INTRODUÇÃO}

A economia global é palco de muitas disputas que envolvem diferentes regiões e pessoas, entre elas a América Latina e sua gente. Nessa área estão em jogo os interesses de camponeses e comunidades indígenas e, também, de trabalhadores, enfermos, e pequenos e médios empresários. Frente a essas tensões, o direito internacional econômico (DIE) apresenta-se ao mundo e aos latino-americanos como o meio para regular conflitos comerciais e de investimentos entre Estados e investidores estrangeiros. Analisando-a, não obstante, essa descrição não parece estar de acordo com as tensões antes assinaladas. Não considera que o DIE transformou-se no principal direito da globalização e, como tal, é árbitro dos interesses e direitos tanto das grandes multinacionais como de quase todas as pessoas. ${ }^{1}$ Isto não significa que o DIE tenha primazia formal sobre os direitos humanos ou o direito ambiental. Porém, muitas vezes, esses e outros direitos internacionais têm papéis um tanto quanto secundários frente às normas de direito do comércio e aos investimentos internacionais.

A crescente importância do DIE justifica estudar com cuidado e especial interesse não somente suas regras jurídicas, mas também a criação de conhecimento em DIE e o papel da academia nessa criação. O papel

1 Em 1963, Baade já enfatizava a importância do DIE para o direito do trabalho e os direitos dos trabalhadores. Ver BAADE, Hans. Teaching International Economic Law. Journal of Legal Education v. 59, p. 61-63, 1963. da academia pode parecer bastante modesto se aceitamos que sua tarefa é manejar o conjunto de regras, determinadas ou determináveis, que governam as relações econômicas internacionais. A partir dessa perspectiva, o DIE operaria por regras relativamente claras que, por sua vez, permitiriam conhecer facilmente os interesses de cada Estado e como estes podem maximizá-los. Em termos comerciais, isto seria ampliar seus mercados cedendo a menor cota de mercado doméstico possível. Em termos de investimento estrangeiro, seria atrair todo o investimento estrangeiro possível, cedendo a menor porção de soberania. ${ }^{2}$

O que essa visão - provavelmente dominante não leva em conta é que o DIE não é somente o resultado das negociações entre Estados. Não se trata do produto de um acumulado de tratados internacionais. $\mathrm{O}$ conhecimento criado pela academia de DIE desempenha um papel central na configuração da ordem econômica internacional. Isto define não somente a interpretação, mas também as fontes do direito que dão sentido, por exemplo, ao termo de tratamento justo e equitativo nos tratados de proteção de investimentos. ${ }^{3} \mathrm{O}$ palco onde operam as regras de direito é uma forma de conhecimento criada pela própria academia de DIE. ${ }^{4}$ Esse conhecimento dá vida aos tratados firmados por todos os Estados, incluindo os latino-americanos, e disciplina a negociação de qualquer obrigação internacional em matéria econômica.

Mas o fato de o DIE ser parte do direito internacional não significa que o conhecimento sobre essa matéria seja criado com uma participação ampla e equitativa. Na realidade, a criação de conhecimento no direito internacional geral tampouco responde a essa caracterização. Segundo Chimni, por exemplo, pode-se argumentar que o DIE é criado com base em um espaço global ocupado pelos interesses de uma classe capitalista transnacional. ${ }^{5}$ Embora

2 Este tipo de análise corresponde a visões realistas ou neo-utilitaristas das relações internacionais. Ver RUGGIE, John. What makes the world hang together? Neo-utilitarianism and the social constructivist challenge. International Organizatio, v. 52, n. 4, 1998.

3 Ver PAPARINSKIS, Martins. The international minimum standard and fair and equitable treatment. Oxford: Oxford University Press, 2013. 4 SIMPSON, Gerry. On the magic mountain: teaching public international law. European Journal of International Law, v. 10, n. 1, 1999; RASULOV, Akbar. The Structure of the International Legal Discourse. In: FLORENCE FOUNDING CONFERENCE. European Society of International Law, 2004. p. 1.

5 Ver CHIMNI, Bhupinder. International institutions today: an imperial global state in the making. European Journal of International Law, v. 15, n. 1, 2004. 
seja difícil vincular esses interesses a espaços geográficos concretos, grande parte do DIE ensinado nas universidades do mundo provém do Norte Global, e isto dá a esses acadêmicos um grande protagonismo na criação de conhecimento de DIE. A academia latino-americana de DIE, indubitavelmente, forma parte da academia global. O DIE, como veremos, apresenta-se hoje ao mundo como uma disciplina global. Na prática, no entanto, os acadêmicos regionais desempenham um papel um tanto quanto secundário na criação do conhecimento em DIE, ainda que não seja assim na disseminação ou aplicação desse conhecimento para resolver disputas concretas.

Nesse contexto, a proposta deste trabalho não é estudar as regras de DIE, mas a criação do conhecimento em torno dessa área do direito internacional, direcionando especial atenção ao papel da academia latino-americana. Ao longo deste trabalho, por isso, referir-se-á tanto a regras como a racionalidades. Esse termo, que se utilizará no sentido weberiano de racionalidade instrumental, refere-se à forma do conhecimento de DIE. Trata-se de um conhecimento que promove certos fins, por exemplo o desenvolvimento econômico e determina que certos meios são necessários para alcançar esses fins. ${ }^{6}$ É importante destacar neste ponto que ainda que Weber reconheça formas plurais de racionalidade, esse autor destaca que somente são objetivas aquelas racionalidades reconhecidas por formas de conhecimento técnico. ${ }^{7}$ No caso do DIE, trata-se de um conhecimento vinculado ao capitalismo econômico que exige, sobre todas as coisas, assegurar a possibilidade de calcular. ${ }^{8}$

Segundo Ruggie, as racionalidades motivam e justificam as ações dos Estados. Estas explicam seu comportamento além do cumprimento de uma regra por sua obrigatoriedade ou por sua possível utilidade. ${ }^{9}$ Ainda que as racionalidades não sirvam para explicar causalmente as ações dos Estados, elas não oferecem uma vi-

6 WEBER, Max. El sentido de la 'neutralidad valorativa' de las ciencias sociológicas y económicas In: ENSAYOS sobre Metodología Sociológica. Buenos Aires: Amorrortu Editores, 1973. p. 222-268.

7 WEBER, Max. El sentido de la 'neutralidad valorativa' de las ciencias sociológicas y económicas In: ENSAYOS sobre Metodología Sociológica. Buenos Aires: Amorrortu Editores, 1973. p. 222-268.

8 WEBER, Max. Parliament and Government in Germany under a New Political Order. In: LASSMAN, P. (Ed.). Weber: Political Writings. Cambridge: Cambridge University Press, 1994. p. 147-148.

9 RUGGIE, John. What makes the world hang together? Neoutilitarianism and the social constructivist challenge. International $\mathrm{Or}$ ganizatio, v. 52, n. 4, 1998. são determinista do mundo, estas servem para explicar por que os Estados não atuam de outra forma. ${ }^{10}$ Assim, a construção de racionalidades é uma ferramenta fundamental para manter a ordem nas relações econômicas internacionais. Estas servem para definir o interesse nos jogadores participantes, determinando suas condutas por meio de incentivos que, em última instância, afetam sua subjetividade. ${ }^{11}$

O argumento central deste artigo é que a academia de DIE cumpre um papel central como geradora de conhecimento nessa matéria, especialmente de suas racionalidades. Isto quer dizer que a academia regional que se ocupa do DIE poderia ter um papel mais importante que a simples reprodução e aplicação de regras de direito. Poderia ser, também, um meio para conhecer e modificar as racionalidades do DIE, criando novas oportunidades para a região.

A primeira parte deste trabalho analisa a visão que tem a academia de direito internacional sobre si mesma, especialmente a academia de DIE e de que forma os acadêmicos em direito internacional contribuem com a ordem econômica global. A segunda parte estuda as racionalidades que emergem do DIE a partir de uma perspectiva latino-americana, enfatizando seu papel constitutivo da ordem econômica global e regional. A última parte toma esses elementos para analisar em detalhe a participação da academia latino-americana na difusão e consolidação da ordem econômica tanto regional como global. A conclusão é que os interesses em jogo no âmbito do DIE são demasiadamente importantes para que a academia regional somente tenha um papel passivo frente à criação de conhecimento nessa matéria. Qualquer que seja a opinião que se tenha sobre a ordem econômica global, seja a favor ou contra a maior participação do Estado na vida econômica, é necessário saber de que forma consolida-se esta ordem e quais são as margens de manobra e possíveis estratégias de mudança. De outra forma, como adverte Aldo Ferrer, a América Latina não poderá "decidir [seu] próprio destino dentro da globalização". ${ }^{12}$

10 RUGGIE, John. What makes the world hang together? Neoutilitarianism and the social constructivist challenge. International $\mathrm{Or}$ ganizatio, v. 52, n. 4, p. 869, 1998.

11 RUGGIE, John. What makes the world hang together? Neoutilitarianism and the social constructivist challenge. International Organizatio, v. 52, n. 4, p. 862-864, 1998; FOUCAULT, Michel. Technologies of the self. In: RABINOV, P. (Ed.). Ethics: Subjectivity and Truth. New York: The New York Press, 1997. p. 223-251.

12 FERRER, Aldo. La importancia de las ideas propias sobre el 


\section{A FUNÇÃO DO DIREITO INTERNACIONAL ECONÔMICO: "ORDENAR" AS RELAÇÕES ECONÔMICAS INTERNACIONAIS}

\section{a. Ordenando o mundo criamos um mundo}

Os acadêmicos localizados no mainstream do direito internacional costumam ver a razão de ser do direito internacional, aquilo que dá sentido a sua profissão, em seu trabalho de ordenar as relações internacionais. ${ }^{13}$ Inspirados no ideal de Kant de paz perpétua, têm por missão regular as imperfeitas relações internacionais, a fim de evitar, antes de tudo, a guerra.

Não é muito diferente no caso do DIE. O mainstream da academia sustenta que é necessário regular as relações econômicas internacionais. No pior dos casos, essas relações, também, podem levar à guerra. $\mathrm{O}$ férreo protecionismo da década de 1930 é apontado por muitos como um dos fatores detonadores da Segunda Guerra Mundial. ${ }^{14}$ A paz, ademais, é fundamental para o desenvolvimento eficiente da atividade econômica internacional. A solução pacífica de controvérsias é um pilar fundamental da ordem econômica internacional, necessária para promover a liberalização progressiva do comércio, os investimentos estrangeiros e o desenvolvimento econômico. ${ }^{15}$

Seguindo essa linha de pensamento, o mainstream da academia em direito internacional caracteriza-se por assumir que já existem relações internacionais entre Estados, tanto políticas quanto econômicas. Essas relações, inclusive, preexistiriam ao direito internacional. Não obstante, esses acadêmicos consideram necessário regular essas relações ou ao menos criar mecanismos adequados para que os Estados possam fazer sua autorregulação. Essa visão domina os acadêmicos neorrealistas e liberais neoinstitucionalistas.

desarrollo y la globalización. Revista Problemas del Desarrollo, v. 173, n. 44, 2013.

13 RASULOV, Akbar. The Structure of the International Legal Discourse. In: FLORENCE FOUNDING CONFERENCE. European Society of International Law, 2004. p. 2.

14 A guerra alfandegária começou com o Smoot-Hawley Tariff Act nos Estados Unidos TREBILCOCK, Michael; HOWSE, Robert. The regulation of international trade. New York: Routledge, 1999. p. 19.

15 PETERSMANN, Ernst-Ulrich. Transformation of the World Trading System through the 1994 Agreement Establishing the World Trade Organization. European Journal of International Law, 1995.
Ruggie critica essas posturas porque, ainda que haja regras que regulam, também há regras que constituem relações. ${ }^{16} \mathrm{Na}$ prática, talvez se trata de categorias ideais e não seja possível encontrar regras totalmente reguladoras ou constitutivas. Mas o DIE, como o direito internacional, não somente ordena as relações internacionais como também as constitui, dando-lhes formas particulares e imprimindo-lhes certas dinâmicas. As relações entre os Estados podem ser algo natural, partindo da premissa que os seres humanos são políticos por natureza. Mas, seja isto certo ou não, é indiscutível que os termos das relações entre Estados, por exemplo, segundo seu caráter civilizado ou incivilizado, não são algo natural, mas criado pelo direito internacional. Algo parecido poder-se-ia dizer das relações em termos de Estados desenvolvidos e em desenvolvimento. Essas categorias dão forma ao que se deve regular. Há Estados que devem tomar certas medidas para que se desenvolvam, outros, porém, apresentam-se ao mundo como desenvolvidos. As correntes críticas do direito internacional têm enfatizado essas racionalidades por décadas. ${ }^{17}$

Apesar disso, o mainstream do DIE opera com base na premissa de que não tem um papel fundamental na constituição das relações econômicas entre os Estados. ${ }^{18}$ A partir dessa visão formalista, mostra-se-o como uma série de regras que se aplicam universalmente, baseadas nos princípios de igualdade, soberania e pacta sunt servanda. ${ }^{19}$ Essas regras seriam objetivas e independentes dos interesses particulares de qualquer Estado, dando uma impressão de igualdade entre todos os atores da comunidade internacional. Essa igualdade manifesta-se, por exemplo, no princípio de reciprocidade nas negociações comerciais. Ou seja, toda concessão comercial

16 RUGGIE, John. What makes the world hang together? Neoutilitarianism and the social constructivist challenge. International Organizatio, v. 52, n. 4, 1998. Ver, também LANG, Andrew. World trade law after neoliberalism: re-imagining the global economic order. Oxford: Oxford University Press, 2011. p. 160.

17 Entre outros, cabe destacar o trabalho de Anthony Anghie. Ver ANGHIE, Anthony. Imperialism, Sovereignty and the Making of International Law. New York: Cambridge University Press, 2004.

18 A principal exceção encontra-se, provavelmente, na literatura do período que vai desde 1950 a 1970, ou seja, durante o auge da teoria da dependência e do direito ao desenvolvimento. Ver, entre outros, BECKER LORCA, Arnulf. International Law in Latin America or Latin American International Law-Rise, Fall, and Retrieval of a Tradition of Legal Thinking and Political Imagination. Harvard International Law Journal, v. 283, 2006.

19 KOSKENNIEMI, Martti. The Politics of International Law. European Journal of International Law, v. 4, 1990. 
requer uma contraprestação. Assim, escutamos, sistematicamente, que os tratados econômicos são atos de cooperação e coordenação, entre dois ou mais Estados, que buscam alcançar objetivos comuns. ${ }^{20}$

Um exemplo dessa tensão entre regulação-constituição é encontrado no direito internacional de investimentos. Esse regime busca proteger os investidores estrangeiros das eventuais lesões que podem dar-lhes os Estados quando recebem seus investimentos. Não obstante, o que ocorre antes do estabelecimento dos investimentos e os resultantes direitos dos investidores são temas ignorados quase completamente. Durante o período anterior ao investimento estrangeiro, aplica-se, sem limitações, a autonomia das partes como se tratasse de atores em igualdade de condições, quando na realidade as grandes empresas multinacionais quase sempre decidem onde e em quais condições investir. Depois do estabelecimento do investimento, quando o Estado seria mais forte graças a seu poder soberano, é necessária a intervenção do DIE para regular a relação entre o "fraco" investidor estrangeiro e o "forte" Estado. ${ }^{21}$

O problema de enfatizar o aspecto regulador do DIE é que não se captam muitas consequências nessa área do direito internacional. Por um lado, a partir da influência do direito ao desenvolvimento, autores latino-americanos criticaram — durante as décadas de 1960 e 1970 a visão formalista do princípio da igualdade. ${ }^{22}$ Por outro lado, o DIE tem efeitos sobre as pessoas e as comunidades. Se existiam dúvidas, as transformações profundas da década de 1990 findaram-nas. O DIE imiscuiu-se na vida de cada um de nós, e ainda assim são poucos que estudam o papel do DIE em nossas vidas diárias.

\section{b. A indeterminação das regras, as racionalidades do direito internacional econômico e o problema da ordem}

As regras que compõem o DIE são indeterminadas, como qualquer regra jurídica, mas isto não quer dizer

20 ABBOTT, Kenneth; SNIDAL, Duncan. Why states act through formal international organizations. Journal of conflict resolution, v. 42, n.1, 1998 .

21 Ver PERRONE, Nicolás. The International Investment Regime and Foreign Investors' Rights: Another View of a Popular Story. 2013. Thesis (PhD) - London School of Economics and Political Science, London, 2013. p. 107-120.

22 GROSS ESPIELL, Héctor. Derecho internacional del desarrollo. In: ESTUDIOS de Derecho Económico II. México: Universidad Autónoma de México, 1980. que cada Estado possa fazer o que queira. Desenvolvimento é o exemplo mais claro: o que é desenvolvimento? Como se alcança o desenvolvimento? A indeterminação da ideia de desenvolvimento põe em risco a ordem econômica internacional. Se cada Estado pudesse fazer o que quisesse para se desenvolver, um objetivo que inclusive pode ter significados muito diferentes em distintas partes do mundo, as possibilidades de conflito seriam muito altas. Para ordenar as relações econômicas satisfatoriamente, então, o DIE necessita de mecanismos que minimizem esse espaço de indeterminação. ${ }^{23}$

Durante o apogeu da Teoria da Dependência, a ideia de desenvolvimento foi utilizada por parte da academia vinculada ao DIE - incluindo a latino-americana - como uma ferramenta emancipadora da ordem existente. ${ }^{24}$ Hoje, não obstante, essa ideia apresenta-se, principalmente, como uma disciplina que os chamados países desenvolvidos impõem aos que estão um pouco menos desenvolvidos. ${ }^{25}$ Não por acaso, enquanto a ideia de desenvolvimento servia tanto para emancipar como disciplinar nas décadas de 1960 e 1970, a ordem econômica internacional era mais porosa e indeterminada. $\mathrm{O}$ regime atual de investimentos, com seus mais de três mil tratados, é justificado precisamente pela incerteza que prevalecia nesses anos. Mais distante dos tratados firmados, a consolidação da interpretação dominante nas arbitragens de investimentos requereu, também, certo conhecimento de DIE. Um passo muito importante nessa direção foi o trabalho de Paulsson sobre arbitration without privity. ${ }^{26}$

Os encarregados de que as regras indeterminadas do DIE tenham na prática um espaço reduzido de indeterminação são os acadêmicos, os experts e quem utiliza essas regras em casos concretos. Isto é percebido hoje na interpretação que fazem os árbitros de investimentos

23 RASULOV, Akbar. The Structure of the International Legal Discourse. In: FLORENCE FOUNDING CONFERENCE. European Society of International Law, 2004.

24 Ver BEDJAOUI, Mohammed. Towards a new international economic order. New York: Holmes \& Meier, 1979. No caso latinoamericano, ver GROSS ESPIELL, Héctor. Derecho internacional del desarrollo. In: ESTUDIOS de Derecho Económico II. México: Universidad Autónoma de México, 1980.

25 ANGHIE, Anthony. Imperialism, Sovereignty and the Making of International Law. New York: Cambridge University Press, 2004. PAHUJA, Sundhya. Decolonising International Law: development, economic growth, and the politics of universality. Cambridge: Cambridge University Press, 2011. p. 132-135.

26 PAULSSON, Jan. Arbitration without privity. ICSID Review, v. 10, n. 2, 1995 
sobre o tratamento justo e equitativo, segundo a qual — sustentam de maneira majoritária — este standard é quase o mesmo em todos os tratados, apesar de as cláusulas serem diferentes. ${ }^{27}$ Algo similar ocorre no direito da OMC. O termo subsídio pode ter distintas interpretações segundo a doutrina econômica, mas na OMC alcançou-se um consenso sobre seu significado. ${ }^{28}$ Tanto no direito dos investimentos estrangeiros como no direito da OMC, uma chave para entender a interpretação dominante reside no consenso sobre os fins desses ordenamentos jurídicos: seja proteger o investimento estrangeiro ou promover a liberalização progressiva do comércio.

Esses consensos são necessários para a manutenção da ordem econômica global. Não obstante, não são o resultado de negociações entre Estados, nem do exercício do poder material dos Estados mais poderosos. É aqui onde a academia de DIE desempenha um papel importante por meio da criação de conhecimento. Em última instância, é certo, questões como o significado do termo subsídio são definidas pelos órgãos jurisdicionais do DIE. Mas estas decisões são delimitadas pelo trabalho dos acadêmicos. O conhecimento nessa matéria desempenha um papel importante na aceitação ou rejeição de qualquer interpretação sobre o tratamento justo e equitativo ou sobre o termo subsídio.

A manutenção da ordem econômica global, por outro lado, requer mais que resolver os possíveis espaços de indeterminação. Uma ordem entre iguais pode mostrar-se instável e, por isso, as racionalidades criadas pela academia de DIE tendem a promover hierarquias - e não necessariamente igualdade - entre os Estados. Essas hierarquias são necessárias para que o DIE possa manter a ordem nas relações econômicas internacionais. Sempre que houver ganhadores e perdedores, fora e dentro de cada Estado, os primeiros ocupam-se de reproduzir a ordem. Proteger o investimento estrangeiro e promover a liberalização do comércio são racionalidades adequadas já que dariam como resultado, como explicam Chang e Wade, ganhadores e perdedores. ${ }^{29} \mathrm{~A}$

27 Ver PAPARINSKIS, Martins. The international minimum standard and fair and equitable treatment. Oxford: Oxford University Press, 2013. 28 Ver LANG, Andrew. Governing As If: Global Subsidies Regulation and the Benchmark Problem. Current Legal Problems, 2014.

29 CHANG, Ha-Joon. Kicking away the ladder: development strategy in historical perspective. London: Anthem, 2002. WADE, Robert. What strategies are viable for developing countries today? The World Trade Organization and the shrinking of development space. Review of International Political Economy, v. 10, n. 4, 2003. igualdade, por outro lado, põe aqueles que se consideram perdedores em posição de tentar alterar a ordem vigente. Como expõem Stiglitz e Rodrik, os Estados em desenvolvimento necessitam de um espaço para experimentar ${ }^{30}$, mas, em um mundo em constante experimentação, é razoável assumir, também, uma crescente desordem global.

A função do conhecimento dominante, então, não é somente estabelecer racionalidades que delimitem o espaço de indeterminação, mas idem outorgar legitimidade às hierarquias econômicas, ocultando a história, nas palavras de Foucault. ${ }^{31}$ Assim, o conhecimento dominante deve ser capaz de mostrar e tratar os parceiros de um tratado de livre comércio ou de um acordo de proteção de investimentos estrangeiros como iguais, ainda que não o sejam.

\section{O DIREITO INTERNACIONAL E SUAS PRINCIPAIS RACIONALIDADES: RECONHECIMENTO POLÍTICO E ECONÔMICO NA AMÉRICA LATINA}

No começo do século XIX, a comunidade latino-americana somou-se às relações internacionais sob a forma de Estados independentes. Nesse momento já existia um ordenamento jurídico que dava forma a essas relações. Por um lado, existiam regras pontuais que regulavam a adesão à comunidade internacional de Estados. Por outro lado, havia uma série de regras gerais que governavam as relações entre os membros da comunidade internacional, incluindo sua adesão. As regras gerais mais importantes eram - e possivelmente seguem sendo - a igualdade e a soberania dos Estados.

A igualdade entre Estados é o principal palco das relações internacionais, mas somente uma análise de como funciona essa igualdade na prática revela-nos a forma em que o direito internacional não somente regula, mas também constitui estas relações. Uma primeira aproximação à igualdade entre Estados mostra-nos

30 RODRIK, Dani. The Global Governance of Trade: As If Development Really Mattered. United Nations Development Programme Background Paper, 2001.; SERRA, Narcís; SPIEGEL, Shari; STIGLITZ, Joseph. Introduction: From the Washington Consensus Towards a New Global Governance. In: THE WASHINGTON Consensus Reconsidered: Towards a New Global Governance. New York: Oxford University Press, 2008.

31 FOUCAULT, Michel. Society must be defended: lectures at the Collège de France, 1975-76. London: Penguin, 2004. p. 98-126. 
que se trata de uma igualdade entre iguais, e não uma igualdade entre soberanos. Aqueles que se reconhecem a si mesmos como soberanos são soberanos sempre que sejam respeitosos para com certas racionalidades econômicas e institucionais. É a procura por essas racionalidades, justamente, o que os torna iguais ao resto dos Estados e não aos outros: os incivilizados, os que não são soberanos. Como veremos, essa distinção entre iguais e outros constitui um eixo fundamental do direito internacional. ${ }^{32}$

A racionalidade por trás do princípio da igualdade não explica causalmente a atitude dos governos latino-americanos no começo do século XIX. Mas nos permite entender por que esses governos buscaram o reconhecimento dos Estados que se reconheciam entre si como soberanos e iguais. Como será exposto, no século XIX, a racionalidade da igualdade foi implementada por meio do standard de civilização. A partir da segunda metade do século XIX, esse standard transformou-se em dois standards estreitamente vinculados: desenvolvimento econômico neoliberal e desenvolvimento institucional do rule of law.

Entendida no contexto dessas racionalidades, a igualdade parece transformar a soberania em uma carta de filiação da comunidade internacional. O reconhecimento tanto político como econômico sempre parece ter um custo alto na ordem internacional: o custo é tornar qualquer aspiração a ser diferente inalcançável. ${ }^{33}$

\section{a. A aspiração a ser parte dos países civilizados: igualdade e soberania}

Fazer parte do conjunto de nações era, para os governos latino-americanos do começo do século XIX, um objetivo central. ${ }^{34}$ Para isso, a racionalidade da igualdade requeria que os Estados latino-americanos adotassem as instituições europeias consideradas civilizadas. Atuar dessa forma era necessário porque o reconheci-

32 ANGHIE, Anthony. Imperialism, Sovereignty and the Making of International Law. New York: Cambridge University Press, 2004.

33 Esquirol explica que a ortodoxia do direito internacional latino-americano tenta alcançar a soberania com argumentos de superioridade racial vinculados com a civilização europeia. ESQUIROL, Jorge. Can International Law Help: an Analysis of the Colombian Peace Process. Connecticut Journal of International Law, 2000. p. 80. 34 BECKER, Félix. Los Tratados de amistad, comercio y navegación y la integración de los estados independientes americanos en el sistema internacional. In: PROBLEMAS de la formación del Estado y de la nación en Hispanoamérica. 1984. mento de quem já era parte da comunidade internacional, ou seja, dos países europeus, era o que acarretava a subjetividade internacional. Segundo a academia internacional da época, a ideia de soberania e Estado tinha como elemento definidor a existência de instituições civilizadas. Para os novos Estados, além disso, também era importante mostrar que essas instituições eram naturalmente adequadas para a América Latina. Fingir o contrário significava assumir que estas terras estavam condenadas à barbárie, a ser o outro. ${ }^{35}$

A racionalidade da igualdade e o standard de civilização são uma racionalidade criada tanto pelos tratados internacionais como pela academia de direito internacional da época. Isto não ocorre por acaso, se aceitarmos que a academia considera que sua missão é ordenar as relações internacionais. O standard de civilização tinha um claro elemento constitutivo na ordem internacional. No século XIX, esse standard significava a imposição de princípios básicos da civilização ocidental, como a propriedade privada, assim como do estabelecimento de contraprestações pelos atos de reconhecimento internacional.

A soberania, porém, nunca foi gratuita. No âmbito econômico, isto pode ser visto nos tratados de paz, amizade e comércio, que muitos governos latino-americanos firmaram com países europeus como forma de obter o reconhecimento como Estados. Por um lado, esses tratados estabeleciam uma enumeração de standar$d s$ de civilização, como a mencionada propriedade privada. Por outro lado, determinavam, de forma bilateral e recíproca, certas regras que respondiam a interesses dos países europeus. Um exemplo paradigmático é a livre navegação nos rios. Embora os Estados que eram partes do tratado beneficiassem-se dessa cláusula, os novos Estados latino-americanos não tinham frota mercantil. Alguns países europeus, por outro lado, eram líderes no transporte marítimo e fluvial. Como alguns autores enfatizam, essa regra - que é resultado do princípio de igualdade e reciprocidade - limitou as possibilidades para que se criasse uma frota mercantil na América Latina. ${ }^{36}$

35 OBREGÓN, Liliana. ¿Para qué un derecho internacional latinoamericano? In: URUEÑA, René (Ed.). Derecho internacional. Poder y limites del derecho en la sociedad global. Bogotá: Uniandes, 2014. p. 37.

36 BECKER, Félix. Los Tratados de amistad, comercio y navegación y la integración de los estados independientes americanos en el sistema internacional. In: PROBLEMAS de la formación del Estado y de la nación en Hispanoamérica. 1984. 
Quando existiam grandes divergências com as instituições civilizadas europeias, além disso, eram necessárias concessões adicionais para obter o reconhecimento internacional. A dívida contraída pelo Haiti em 1825, por exemplo, é o resultado advindo do fato de que muitos de seus cidadãos, segundo os standards de civilização imperantes (ou, melhor dito, incivilização), eram escravos, quer dizer, propriedade privada de sujeitos de outros Estados. Assim, o Haiti teve que contrair um empréstimo para poder compensar a perda de direitos que existiam segundo as leis vigentes na metrópole. ${ }^{37}$

O reconhecimento dos Estados latino-americanos como soberanos, por outro lado, estava condicionado a que seus governos atuassem conforme a racionalidade criada e reproduzida pelo direito internacional. Se os Estados latino-americanos não cumpriam com os standards de civilização fundamentais para a ordem internacional, por exemplo o respeito da propriedade, a comunidade internacional reservava seu direito de intervir para fazê-los valer. Em outras palavras, reservava-se o direito de desconhecer o caráter soberano dos novos Estados. O princípio de não intervenção, corolário-chave do reconhecimento de soberania, somente se aplicava aos Estados que atuavam de forma civilizada. Essa premissa justificava a proteção diplomática na América Latina e também a instituição consular em países como a China e o Japão. ${ }^{38}$

A ideia de soberania, então, parece mais uma forma de definir uma filiação a um clube que um termo para descrever a capacidade de um povo de governar-se a si mesmo. A prática dos novos Estados e a posição de seus acadêmicos assim o confirmam. $\mathrm{Na}$ maioria dos casos de intervenção, os representantes dos novos Estados não desafiavam as regras impostas pelos standards de civilização, mas afirmavam que se comprometiam com esses standards ou que estavam em um rápido processo de implementação das leis ocidentais. ${ }^{39}$ Essas reações podem ser explicadas consoante ao conhecimento dominante de direito internacional e demonstram o poder constitutivo da racionalidade da igualdade nas relações

37 OBREGÓN, Liliana. ¿Para qué un derecho internacional latinoamericano? In: URUEÑA, René (Ed.). Derecho internacional. Podery límites del derecho en la sociedad global. Bogotá: Uniandes, 2014. p. 32-35. 38 BECKER LORCA, Arnulf. Mestizo International Law: a Global Intellectual History 1842-1933. Cambridge: Cambridge University Press, 2014. p. 3-8.

39 BECKER LORCA, Arnulf. Mestizo International Law: a Global Intellectual History 1842-1933. Cambridge: Cambridge University Press, 2014. p. 3-8. internacionais. Nenhum dos novos Estados pretendia ser reconhecido na ordem internacional como diferente - ou seja - como suficientemente autônomo como para se dar suas próprias instituições. No contexto da racionalidade da igualdade, em outras palavras, a ideia de soberania é quase antagônica à ideia de autonomia. Uma comunidade de pessoas deveria renunciar a sua autonomia para ser parte do clube de Estados soberanos.

\section{b. A aspiração a ser parte do mundo desenvolvido: igualdade, desenvolvimento e rule of law}

Após o processo de descolonização, consolida-se uma transformação importante à ordem internacional, já que grande parte do território mundial é reconhecido como parte integrante de Estados iguais e soberanos. A comunidade internacional de Estados mantém o controle sobre a subjetividade estatal internacional. Governo, território e população não são mais que fatores materiais que na prática, como no caso da Palestina, não implicam soberania. Não obstante, uma vez outorgado o reconhecimento, a igualdade e a soberania são menos discutíveis. Essa troca afeta a racionalidade da igualdade tornando mais difícil disciplinar a conduta estatal a partir da dicotomia civilizado-incivilizado. Mas a influência sobre os assuntos internos de muitos Estados não desaparece, na medida que é necessária para manter a ordem econômica global. A academia de DIE realiza essa tarefa a partir de outros meios e fins, de outras racionalidades.

Esse momento histórico coincide com o surgimento de uma nova forma de ordenar as relações internacionais, que dará ao DIE seu protagonismo atual. A partir da segunda metade do século XX, o direito internacional racionaliza grande parte das relações entre os Estados - tanto a nível regional como global - a partir da questão econômica. Trata-se, mais concretamente, da racionalidade do desenvolvimento econômico. ${ }^{40}$ Todos

40 A importância da racionalidade do crescimento econômico motorizado pelo mercado nos Estado liberais e neoliberais é desenvolvida por Weber e Foucault. SWEDBERG, Richard. Max Weber's Contribution to the Economic Sociology of Law. Annual Review of Law and Social Science, v. 61, 2006. FOUCAULT, Michel. Security, Territory and Population: lectures at the collège de france 1977-1978. Chippenham, UK: Palgrave Macmillan, 2009. p. 95-99; 341-358; FOUCAULT, Michel. The Birth of Biopolitics: Lectures at the Collège de France, 1978-1979. Chippenham, UK: Palgrave Macmillan, 2010. p. $144 ; 252$. 
os Estados são formalmente iguais, mas não são economicamente iguais. Os Estados que anteriormente eram administradores da civilização são agora os administradores do desenvolvimento e o DIE vai reconhecer essa diferença a partir do mesmo projeto de Bretton Woods. Por exemplo, duas das instituições-chave da ordem econômica global, o Fundo Monetário Internacional (FMI) e o Banco Mundial, têm mecanismos de votação que reflitam essa hierarquia ou desigualdade.

Como ocorria com o standard de civilização, existem dois fatos sociais chave que não requerem maior comprovação no caso da racionalidade do desenvolvimento. Um é o reconhecimento generalizado de alguns Estados como desenvolvidos e o outro é o desejo do resto de alcançar esse desenvolvimento. $\mathrm{O}$ reconhecimento como desenvolvido não depende de que se trate de um dos países mais desiguais do mundo, ou que ali se haja iniciado as duas crises financeiras mais graves dos últimos cem anos: ninguém questiona o status dos Estados Unidos como um país desenvolvido. Pelo contrário, existe todo um conhecimento focado em torno da ideia de desenvolvimento, cujo objetivo é dar forma à conduta dos países considerados em desenvolvimento. Esse conhecimento econômico manifesta-se na forma de meios e fins, ou racionalidades, e é o resultado do trabalho de acadêmicos e experts de organismos internacionais econômicos, como o Banco Mundial, o FMI, e a Organização para a Cooperação e Desenvolvimento Econômico (OCDE).

Os Estados chamados desenvolvidos aprovam o desejo de desenvolver-se que têm os outros Estados. Às vezes, poderia dizer-se que o celebram. A partir do fim da Segunda Guerra Mundial, oferecem ajuda financeira, técnica e política para o desenvolvimento, que também é funcional a outros interesses desses Estados: desde lutar contra o comunismo a manter a ingerência nos assuntos internos destes países. ${ }^{41}$ Embora os países do Sul global não estejam obrigados a aceitar essa ajuda (ou a mesma racionalidade do desenvolvimento), poucos estão dispostos a serem subdesenvolvidos, da mesma forma que ninguém estava disposto a ser o incivilizado no século XIX. Há pressões para seguir esse caminho, como as condicionalidades do FMI, mas não se trata, somente, de coerção mas idem de aceitação de certos meios como idôneos para alcançar o desenvolvimento.

41 Ver supra n. 25.
Diferentemente do que ocorria com a racionalidade da igualdade e o standard de civilização, não obstante, a racionalidade do desenvolvimento adota duas formas historicamente diferenciadas. Os Estados do Sul global, ao menos durante as primeiras décadas do pós-guerra, vão questionar a racionalidade do desenvolvimento impulsionada pelos Estados Unidos e Europa ocidental. Desconfiam porque creem que esses Estados alcançaram seu bem-estar material a partir de relações assimétricas coloniais ou de dominação informal ${ }^{42}$, eliminando - por exemplo - a possibilidade de uma frota mercantil na América Latina. Durante as décadas de 1950 a 1970, seguindo essa linha, os Estados latino-americanos buscaram desenvolver-se por meio de uma racionalidade própria, inspirada na Teoria da Dependência.

Impulsionada por acadêmicos do Sul global, essa racionalidade do desenvolvimento apresenta-se como uma demanda, uma forma de emancipação, que exige dos Estados Unidos e da Europa ocidental a reorganização das relações econômicas internacionais ${ }^{43}$. Trata-se de implementar regras que permitam ao resto dos Estados conduzir sua economia, principalmente o uso de recursos minerais, e utilizar esses recursos para alcançar o desenvolvimento industrial. Esta fase emancipadora pode ser vista no discurso da teoria da dependência sobre comércio e investimentos, que desconfia do livre comércio e do capital proveniente das antigas potências coloniais. ${ }^{44}$ Considera, por outro lado, que a criação de capital nacional é necessária para alcançar tanto o desenvolvimento econômico como uma democracia saudável. ${ }^{45}$ Tratava-se, segundo Prebisch, de dar à população desses Estados as mesmas condições econômicas e democráticas dos Estados Unidos e Europa ocidental. ${ }^{46}$

42 GILPIN, Robert. Global Political Economy: understanding the International Economic Order. Princeton, N.J.: Princeton University Press, 2001. p. 286-288.

43 Essa demanda articula-se por meio do direito ao desenvolvimento. Ver Héctor Gross Espiell, supra n. 22.

44 No caso latino-americano, os expoentes mais importantes desta escola são Raúl Prebisch, Celso Furtado, Fernando H. Cardozo e Enzo Faletto. Ver BIELSCHOWSKY, Ricardo. Cincuenta años del pensamiento de la CEPAL: una reseña. In: CINCUENTA años del pensamiento de la CEPAL: textos selecionados. Santiago: Fondo de Cultura Económica/CEPAL, 1998. p. 9-61.

45 CUADERNO, Miguel. The Anti-Capitalist Attitude. In: Private investment: the key to international industrial development. New York: McGraw Hill, 1958. PREBISCH, Raúl. El desarrollo económico de la América Latina y algunos de sus principales problemas. Desarrollo Económico, 1986.

46 PREBISCH, Raúl. El desarrollo económico de la América Latina y algunos de sus principales problemas. Desarrollo Económico, 1986. p. 479. 
Durante esse período, a produção acadêmica latino-americana ressaltava a importância de um direito internacional ao desenvolvimento como base de uma nova ordem econômica global. ${ }^{47}$ Tratava-se de uma visão alternativa das relações econômicas entre os Estados: de uma ordem e uma racionalidade distintas. Essa visão refletiu-se nas resoluções da Assembleia Geral da Organização das Nações Unidas. As resoluções mais importantes referem-se à soberania permanente sobre os recursos naturais ${ }^{48} \mathrm{e}$ à carta de direitos e deveres econômicos dos Estados. ${ }^{49}$ Algumas dessas ideias foram consolidadas - ainda que por um curto período - com a criação da Comissão Econômica para a América Latina e o Caribe (CEPAL) e da Conferência das Nações Unidas sobre Comércio e Desenvolvimento (UNCTAD, em inglês)..$^{50}$

Essa visão emancipadora do desenvolvimento, não obstante, foi derrotada no final da década de 1970 pela racionalidade do desenvolvimento impulsionada pelos Estados Unidos e Europa ocidental. Para essa visão, a chave não era o planejamento industrial estatal, mas a atração de investimento estrangeiro privado a fim de utilizar de maneira eficiente os recursos econômicos. ${ }^{51}$ Essa racionalidade do desenvolvimento é neoliberal e o auge destas ideias vai circular a partir do norte em direção ao sul. ${ }^{52}$ Para alcançar o desenvolvimento econômico, dizia o paradigma neoliberal da década de 1990, é necessário que os Estados comportem-se de acordo com uma nova disciplina institucional e fiscal. Essas políticas são desenhadas e sua implementação monitorada com base no Banco Mundial, o FMI, a OCDE e a nova unidade da UNCTAD encarregada de investimento estrangeiro. ${ }^{53}$

47 GROSS ESPIELL, Héctor. Derecho internacional del desarrollo. In: ESTUDIOS de Derecho Económico II. México: Universidad Autónoma de México, 1980. p. 230-233.

48 Resolução 1803 (XVII) da Assembleia Geral da ONU, de 14 de dezembro de 1962.

49 Resolução 3281 (XXIX) da Assembleia Geral da ONU, de 12 de dezembro de 1974.

50 GROSS ESPIELL, Héctor. Derecho internacional del desarrollo. In: ESTUDIOS de Derecho Económico II. México: Universidad Autónoma de México, 1980. p. 230-233.

51 OGLE, Vanessa. State Rights against Private Capital: The "New International Economic Order" and the Struggle over Aid, Trade, and Foreign Investment, 1962-1981. Humanity, v. 211, 2014.

52 O Banco Mundial, por exemplo, foi chave na implementação de reformas agrárias sugeridas por experts como Hernando de Soto. Ver ESQUIROL, Jorge. Can International Law Help: an Analysis of the Colombian Peace Process. Connecticut Journal of International Law, 2000. p. 153-154.

53 No caso da UNCTAD, SAGAFI-NEJAD, Tagi; DUNNING,
Nesse contexto, os organismos internacionais começaram a outorgar financiamento para implementar as instituições necessárias para o desenvolvimento neoliberal. Muitas universidades do norte apoiaram esse projeto. Assim, toma forma a racionalidade da igualdade e o rule of law, segundo a qual os países em desenvolvimento devem incorporar as instituições dos Estados Unidos e da Europa Ocidental. Trata-se de reconhecer direitos de propriedade fortes, iniciar uma reforma do Estado focada em privilegiar o papel do mercado como garantia do desenvolvimento econômico, e manter uma estabilidade fiscal e macroeconômica. ${ }^{54}$ Esta é uma racionalidade que busca facilitar a atividade econômica global e a atração de investimento estrangeiro privado.

No que se refere, especificamente, aos investimentos estrangeiros, a racionalidade neoliberal do desenvolvimento foi consolidada por meio de tratados assimétricos de promoção e proteção de investimentos. Esses tratados protegem o investimento de ambos os Estados, mas, na prática, a grande maioria dos fluxos provêm dos países do Norte Global. Fato não muito diferente daquele que se sucedeu com os tratados de amizade, navegação e comércio. No caso do transporte marítimo e fluvial, haveria transporte na América Latina, mas seria um negócio de estrangeiros. No caso dos investimentos estrangeiros hoje, haverá crescimento econômico. mas dependerá de e será dirigido principalmente por capitais globais. ${ }^{55}$ As implicações desse controle estrangeiro são deixadas de lado ou minimizadas por grande parte da literatura atual sobre arbitragem internacional de investimentos. Esse esquema, não obstante, estaria dando lugar ao surgimento de uma classe capitalista transnacional que atua como se fosse externa às necessidades $\mathrm{e}$ aos valores de cada comunidade. ${ }^{56}$

$\mathrm{Na}$ implementação dessa ordem econômica neoliberal, o papel da Organização Mundial do Comércio (OMC) também foi vital. Esse organismo foi durante

John. The UN and Transnational Corporations: from code of conduct to global compact. Bloomington: Indiana University Press, 2008. p. 124-126.

54 Ver ROBERTS, Alasdair. The logic of discipline: global capitalism and the architecture of government. New York: Oxford University Press, 2010.

55 Ver LALL, Sanjaya. Reinventing industrial strategy: the role of government policy in building industrial competitiveness. In: UNITED NATIONS CONFERENCE ON TRADE AND DEVELOPMENT, 28, 2004. p. 31; CHANG, Ha-Joon. Regulation of Foreign Investment in Historical Perspective. The European Journal of Development Research, v. 16, n. 3, 2004. p 712.

56 Ver supra n. 5. 
o final da década de 1990 o farol de muitas reformas neoliberais em termos comerciais. Sua função, nas palavras de Chang, foi chutar a escada se acaso algum país pretendesse voltar a implementar políticas de promoção industrial. ${ }^{57}$ Ao limitar consideravelmente o apoio à indústria doméstica, incorporar um forte sistema de proteção à propriedade intelectual e facilitar a mobilidade de bens e serviços, a OMC consolida o capitalismo internacional das cadeias globais de valor. Tornar-se parte dessas cadeias é vital na atual configuração das relações econômicas internacionais. ${ }^{58}$

Nesse contexto de transformação da década de 1990, grande parte da academia latino-americana de DIE limitou-se, principalmente, a seguir as mudanças e avanços institucionais. Ainda que houvesse críticas, como as de Correa na área de propriedade intelectual ${ }^{59}$, a maioria da literatura latino-americana ocupou-se de sistematizar os instrumentos legais, reproduzindo, de maneira explícita ou implícita, racionalidades que reproduzem a ordem econômica global neoliberal. ${ }^{60}$

\section{A academia latino-americana de direito INTERNACIONAL ECONÔMICO E SUA CONTRIBUIÇÃO À ORDEM ECONÔMICA GLOBAL}

A academia latino-americana de DIE forma parte da academia internacional. O DIE apresenta-se hoje ao mundo como uma disciplina global, apesar dos tratados bilaterais de livre comércio, do alto grau de fragmentação de convenções que existe no regime internacional de investimentos e dos distintos contextos políticos, econômicos e sociais de cada país e região. A academia nessa matéria não vê esses contextos diferentes como um problema sério, já que às divergências textuais, sociais e políticas opõem-se racionalidades globais que servem para minimizar diferenças e ordenar as relações econômicas internacionais. O verdadeiramente global e universal, ergo, é o conhecimento de DIE. A comunida-

$57 \quad$ Ver supra n. 29.

58 Ver Comunicado do G20, 15-16 novembro de 2015. Disponível em: <http://www.gpfi.org/ publications/g20-leaders-communiqu-antalya-summit-2015>.

59 CORREA, Carlos. Intellectual property rights, the WTO and developing countries: the TRIPS agreement and policy options. New York: Zed books, 2000.

60 ENRÍQUEZ ROSAS, José. Derecho internacional económico: instituciones y críticas contemporâneas. México, Porrúa, 2006. de regional envolvida nessa matéria não representa uma descontinuidade normativa nem social com a comunidade global: com somente algumas poucas exceções, trata-se de um subgrupo dentro dessa mesma comunidade epistêmica. ${ }^{61}$ Não é por acaso, por exemplo, que a rede latino-americana de DIE tenha sido criada no seio e seja um capítulo a mais da rede internacional. ${ }^{62}$

Dada a importância da América Latina nas relações econômicas internacionais, que foi uma das principais vozes críticas entre os anos 1950 e 1970, os acadêmicos dessa região têm algum peso na criação de conhecimento em DIE. Frente à diversidade de textos legais e à indeterminação própria do direito, a existência de um DIE global mostra que existe um consenso na criação e reprodução do conhecimento. Hoje, grande parte da academia latino-americana é parte desse consenso.

Por um lado, a simples recepção e ensino de conhecimentos consolida as racionalidades que constituem e ordenam as relações econômicas internacionais. Por outro lado, as contribuições que fazem muitos experts regionais de DIE aos princípios e às regras vigentes consolidam a ordem econômica global. Esses experts representam a região de maneira indireta, e muitos dão sua aquiescência à ordem atual. A participação de juízes e árbitros latino-americanos, que quase sempre também são acadêmicos, é um argumento a favor da legitimidade de um regime internacional, sem importar o conteúdo de suas decisões.

\section{a. A contribuição por meio do ensino}

Como a maior parte do ensino de direito na América Latina, o ensino de DIE tem em vista, principalmente, o mercado profissional e percebe o direito como uma prática que deve ser aprendida e aplicada a casos concretos. ${ }^{63}$ Essa perspectiva deixa de lado o papel constitutivo

61 Essas exceções limitam-se quase exclusivamente à área de propriedade intelectual. Ver supra n. 59 e o trabalho de Rafael Pérez Miranda na área de biotecnologia e sementes.

62 Cf.: <http://iellatina.blogspot.com/>. Vale esclarecer que o autor é membro ativo desta rede.

63 Ver LISTA, Carlos. La construcción de la conciencia jurídica: los objetivos educativos y la formación del abogado. 5 Anuario CIJS, v. 381, 1999-2000. p. 394-395; 400; PÉREZ PERDOMO, Rogelio. Desafíos de la educación jurídica latinoamericana en tiempos de globalización. El otro derecho, p. 19-20, 2008. A formalização do ensino do direito como prática esconde o lado constitutivo do processo de aprendizagem. Como explica Lista, não somente se dá conhecimento jurídico, mas também se formam consciências jurídicas. LISTA, Carlos. La construcción de la conciencia jurídica: los objetivos educativos y la formación del abogado. 5 Anuario - CIJS, v. 
do direito e o contexto da ordem vigente. Ainda que essa tendência seja comum a todas as áreas do direito, é mais fácil para os estudantes ter consciência de que o direito doméstico, seja de propriedade ou de contratos, por exemplo, é fruto de uma disputa entre interesses políticos distintos. Isto é assim por uma questão de proximidade social e cultural; o contexto está lá fora da aula. Em DIE, por outro lado, isto é mais difícil dada a suposta distância das relações econômicas internacionais, que somente interessariam às elites e teriam pouco a ver com a vida cotidiana dos trabalhadores ou dos enfermos. ${ }^{64}$

As competições internacionais são um exemplo do ensino de DIE como uma prática ${ }^{65}$. Uma das atividades que mais desperta interesse nos estudantes, a qual demonstra mais empenho, é a de pensar e resolver disputas, ou seja, reparar a ordem perdida em uma relação econômica internacional concreta. Nessas competições, os estudantes viajam a diferentes lugares do mundo para se enfrentarem com os experts que executam diariamente a racionalidade do desenvolvimento, ou seja, dos investimentos estrangeiros e do comércio internacional. Em relação à preparação para essas competições, a atividade docente consiste em treinar os estudantes a operar dentro das racionalidades dominantes e da ordem estabelecida. As competições internacionais promovem uma perspectiva que assume o caráter regulador do DIE, reduzindo a importância dada ao caráter constitutivo que tem o conhecimento nessa matéria. Assim, as competências promovem a formação de novos experts para nutrir a comunidade que diariamente consolida a ordem existente. Por exemplo, é uma prática dos escritórios de advocacia internacionais recrutar "recursos humanos" nessas competições.

\section{b. A contribuição por meio da defesa dos interesses do Estado}

A contribuição por meio da defesa dos interesses estatais é outra forma paradigmática de consolidar a or-

381, 1999-2000. p. 386-387.

64 Gerry Simpson reconhece que um dos problemas da academia de direito internacional é a omissão do contexto. Ver supra n 4, p. 88. 65 Ver BRAVO, Karen. International Economic Law in US Law Schools: Evaluating its Pedagogy and Identifying Future Challenges. In: COLIN, Picker et al. (Ed). International Economic Law: the state and future of the discipline. London: Hart Publishing, 2008. p. 155. As competições internacionais mais importantes são Jessup, Vis, FDI Moot e ELSA-WTO. O autor tem conhecimento direto sobre a Vis e a FDI Moot, e conhecimento indireto sobre as outras duas. dem existente, na qual participam acadêmicos e experts latino-americanos. No século XIX, por exemplo, Carlos Calvo não criticava a distinção entre países civilizados e não civilizados. Pelo contrário, Calvo defendia os Estados latino-americanos dentro dessa racionalidade, com o argumento de que estes Estados respeitavam a propriedade privada tal como os Estados europeus ou os Estados Unidos. ${ }^{66} \mathrm{O}$ mesmo faziam os acadêmicos japoneses ou chineses, por certo, que buscavam demonstrar que seus países haviam comportado-se conforme a racionalidade imperante, ao ter incorporado as instituições de direito privado e público dos países ocidentais. ${ }^{67}$

Nesses debates e discussões, os acadêmicos latino-americanos - como os acadêmicos de outros países não centrais - também influenciaram na construção do direito internacional. Becker Lorca afirma que existiu uma certa circularidade ou reflexividade entre os acadêmicos e os experts de todo o mundo. ${ }^{68}$ Essa circulação de ideias, opina-se, deve emoldurar-se dentro das racionalidades de igualdade e soberania, e a dicotomia civilizado-incivilizado. Becker Lorca descreve um tipo de resistência que faz uso estratégico do conhecimento dominante de direito internacional. Esse uso pode servir para se colocar em vantagem em uma controvérsia pontual ou doutrinária, mas é dificultoso pensar em um cenário onde possa modificar as racionalidades dominantes. A participação de acadêmicos latino-americanos e asiáticos que descreve Becker Lorca pode até chegar a ser descrita como uma forma de tragédia, já que - ao final de contas - pouco muda no conhecimento dominante (por exemplo, com base na evolução do standard da civilização para o standard de desenvolvimento).

Algo parecido ocorre na atualidade no DIE. A defesa dos interesses argentinos nas arbitragens pela crise de 2001 foi altamente ineficaz quando tentou responder com argumentos próprios de direito constitucional argentino, alheios ao DIE. ${ }^{69}$ Quando esse país trocou sua estratégia e começou a utilizar argumentos de direito internacional, sua posição melhorou e obteve algumas vitórias em arbitragens de investimentos. Pode-se dizer que, inclusive, fez contribuições importantes ao tema da

\footnotetext{
66 Ver supra n. 18 p. 302.

67 Ver supra n. 38, p. 4-5.

68 Ver supra n. 38, p. 7.

69 A posição argentina era conhecida como doutrina Rosatti. Ver ROSATTI, Horacio. Los tratados bilaterales de inversión: El arbitraje internacional obligatorio y el sistema constitucional argentino. La Ley, v. 67, n. 198, 2003.
} 
exceção por estado de necessidade no que toca à ordem vigente. Mas não há dúvidas de que, ao mesmo tempo, ajudou a consolidar a arbitragem de investimento. Esse país, apesar da grande lista de condenações contra si, não denunciou seus tratados bilaterais de investimento tampouco iniciou um processo de revisão interno.

O mesmo pode-se argumentar sobre o papel do Brasil na OMC, que é visto como um caso de êxito pela literatura. ${ }^{70}$ Essa opinião deve-se, entre outras explicações, às vitórias alcançadas na área de subsídios agrícolas. $\mathrm{O}$ que essas vitórias mostram é como um país como o Brasil pode vencer os Estados Unidos ou a União Europeia com as regras vigentes. Com isto, a literatura estaria fazendo duas coisas. Por um lado, mostra as possibilidades que têm alguns países emergentes na OMC. Isto é muito valioso, por certo. Por outro, legitima as regras da OMC frente ao resto do mundo.

A contribuição à ordem econômica global feita pelos defensores dos Estados latino-americanos também é relevante quando, por suas grandes qualidades, esses indivíduos são contratados pelos escritórios globais de advogados. No âmbito da arbitragem de investimentos, vários advogados proeminentes da região foram logo contratados por estes escritórios. As relações que se estabelecem entre as defesas dos Estados e estas firmas globais não fazem mais que consolidar a ordem vigente. Estas relações fortalecem-se especialmente graças ao direcionamento de pessoas defensoras dos Estados aos escritórios de advocacia globais.

\section{c. A contribuição por meio da pesquisa}

Os pesquisadores latino-americanos em DIE realizam uma contribuição importante para a consolidação da ordem econômica global. Isso se deve a motivos acadêmicos e profissionais. Por um lado, hoje muitos dos acadêmicos da região formam-se no exterior, a língua dominante no DIE é o inglês, e muitos latino-americanos de renome estão fora de seus países. ${ }^{71} \mathrm{~A}$ isto se somam a pressão dos rankings universitários e a crescente necessidade de publicar em revistas reconhecidas internacionalmente. Por outro lado, na América Latina, existe uma proximidade entre muitos acadêmicos, a de-

70 SHAFFER, Gregory et al. The trials of winning at the WTO: what lies behind Brazil's success. Cornell International Law Journal, v. 41, n. 2, 2008.

71 Ver supra n. 52, p. 148-154. fesa dos Estados e escritórios de advocacia. Isto é compreensível quando a ideia de uma carreira acadêmica em direito é algo ainda tido como novidade na região.

Somadas, essas circunstâncias não fazem com que nossa academia perca suas características latino-americanas. Os acadêmicos em geral ocupam-se da situação particular de um país ou da região. O que ocorre é que muitos trabalhos abordam as problemáticas com base em grandes linhas epistemológicas desenvolvidas nos centros acadêmicos do Norte. Em uma palavra, não é que a academia regional esquece-se da região, mas sim utiliza enfoques produzidos em outras latitudes, incorporando ainda que seja de maneira implícita as racionalidades que compõem esses trabalhos. ${ }^{72}$

Essa atitude é explicável em um mundo onde o reconhecimento internacional é muito importante para as universidades e seus acadêmicos. Para os que estão na América Latina, especialmente, este reconhecimento é valioso se provém das universidades do norte. ${ }^{73}$ As citações em revistas especializadas dos centros acadêmicos mais importantes são as mais relevantes, quer dizer, aquelas revistas dirigidas a partir de fora da região. Ser reconhecido nestes centros é difícil por si mesmo e, sem dúvidas, é ainda mais difícil se um indivíduo propele ideias que se opõem às racionalidades dominantes.

Assim, vemos como o conhecimento em DIE não somente ordena o comportamento dos Estados, mas idem dos acadêmicos. Isto não é uma surpresa já que críticas agudas e profundas põem em risco a ordem nas relações econômicas internacionais. O problema para os que querem promover a mudança com base na academia é que, para alterar, é necessário sugerir alguma forma de crise no paradigma de DIE vigente. ${ }^{74}$

Um exemplo do papel que desempenha a academia regional pode ser encontrado no direito de investimento estrangeiro, provavelmente a área mais controversa do DIE na atualidade. A América Latina é a região mais processada por investidores estrangeiros e alguns de seus governos têm sido muito duros com a arbitragem de investimentos. Não obstante, não é a região a partir da qual têm sido feitas as principais contribuições aca-

72 ESQUIROL, Jorge. Can International Law Help: an Analysis of the Colombian Peace Process. Connecticut Journal of International Law, 2000. p. 153-154.

73 Ver supra n. 35, p. 51.

74 KUHN, Thomas. The essential tension: selected studies in scientific tradition and change. Chicago: University of Chicago Press, 1977. 
dêmicas críticas. O ponto, especificamente, não é que a academia regional não critica ou não tem criticado esta área do DIE. Mas, se olhamos o contexto global, as críticas mais fortes provêm de acadêmicos canadenses e europeus. Os primeiros responderam duramente logo que seu país fora condenado em mais de uma oportunidade no que toca ao Tratado de Livre Comércio da América do Norte. ${ }^{75}$ Um grupo de acadêmicos europeus, mais recentemente, manifestou-se publicamente contra a arbitragem de investimentos no que tange às negociações transatlânticas. ${ }^{76}$

$\mathrm{Na}$ América Latina, de outro giro, as críticas governamentais não têm sido acompanhadas de argumentos de DIE considerados novos, nem de um apoio majoritário da academia regional. Trata-se, em uma palavra, de uma crítica moderada. ${ }^{77}$ Esta tendência vincula-se tanto às racionalidades vigentes, quer dizer, à necessidade de alcançar o desenvolvimento, como às dinâmicas acadêmicas e profissionais que dominam a região.

\section{Considerações finais}

O objetivo deste trabalho é inspirar um debate sobre o papel da academia latino-americana de DIE, oferecendo uma visão construtivista do trabalho dos acadêmicos. Com base em uma visão focada na prática, a resposta é que o papel da academia é analisar as regras e servir de apoio para as negociações internacionais que avançam freneticamente. O propósito consiste em oferecer aos Estados latino-americanos os melhores resultados possíveis na atual ordem econômica global. Essa postura dirá-nos que os Estados e as empresas latino-

75 Ver VAN HARTEN, Gus. Investment treaty arbitration and public law. New York: Oxford University Press, 2007.; SCHNEIDERMAN, David. Constitutionalizing Economic Globalization. Investment Rules and Democracy's Promise. New York: Cambridge University Press, 2008. Ver, também, a declaração de Osgoode proferida por Van Harten e Schneiderman, onde somente dois dos que assinam têm cargos acadêmicos ou de investigação na América Latina. Disponível em: <http://www.osgoode.yorku.ca/publicstatement-international-investment-regime-31-august-2010/>.

76 STATEMENT of Concern about Planned Provisions on Investment Protection and Investor-State Dispute Settlement (ISDS) in the Transatlantic Trade and Investment Partnership (TTIP). University of Kent. Disponível em: <https://www.kent.ac.uk/law/ isds_treaty_consultation.html>.

77 Becker Lorca argumenta que a academia Latino-Americana de Direito Internacional moderou-se após a década de 1970. Ver supra n. 18 , p. 288 . -americanas necessitam de advogados que defendam seus interesses aqui e agora, e que a academia tem, então, um papel formador e de apoio muito importante.

Essa visão explica por que muitos Estados da região encontram-se envolvidos na negociação de tratados de livre comércio, enquanto outros - que se sentem retardatários nessa corrida - tentam evitar alguns obstáculos institucionais para poderem aderir-se. ${ }^{78}$ Sua atitude é razoável se assumirmos que esses tratados são a nova normalidade e que, portanto, quanto mais se demore um país a se aderir, provavelmente, mais custoso será fazê-lo no futuro. ${ }^{79}$ Mas qualquer que seja a opinião que se tenha sobre os tratados de livre comércio, não é necessário aceitar que esta realidade seja ineludivel. A academia latino-americana de DIE pode fazer mais que aprender a manejar regras. Também, pode trabalhar para transformar esta realidade.

Os interesses em jogo são demasiadamente importantes para se contentar com uma atitude passiva. É importante que os acadêmicos trabalhem pela defesa dos interesses concretos que se enfrentam em uma disputa, mas também que a academia some seus esforços por um DIE que permita aos Estados latino-americanos implementar políticas que respondam a suas necessidades. Trata-se de ensinar não somente para a consultoria privada ou pública, mas também para cidadãos responsáveis no contexto local e global. ${ }^{80} \mathrm{~A}$ região necessita que os acadêmicos sejam conscientes do papel constitutivo que tem a academia na ordem econômica global. Caso contrário, as alternativas políticas estarão sempre limitadas a se juntar à nova coalizão global de mercados abertos, nas palavras de Robert Zoellick, ou ao ostracismo econômico. ${ }^{81}$

Manter aberta a possibilidade de pensar alternativas, é certo, não é uma tarefa fácil. A academia latino-americana de DIE tem a possibilidade de ser mais cons-

78 Esta é a situação atual do Brasil e do Uruguai, que não podem negociar tratados de livre comércio pelas limitações que lhes impõe o Mercosul. Cf.: < http://www.lanacion.com.ar/1814925hacia-un-nuevo-mercosur>; Cf.: <http://g1.globo.com/economia/ noticia/2015/05/uruguai-esta-de-acordo-com-brasil-sobre-tratadoentre-mercosul-e-ue.html>.

79 KOLSKY LEWIS, Meredith. The Trans-pacific Partnership Agreement and Development. In: VOON, Tania (Ed.). Trade Liberalisation and International Co-operation: A Legal Analysis of the TransPacific Partnership Agreement. Cheltenham, UK: Edward Elgar, 2013. p. 28-49.

80 Ver supra n. 4, p. 84.

81 ZOELLICK, Robert. Unleashing the trade winds. The Economist, v. 5, dec. 2002. 
ciente de seu papel constitutivo da ordem econômica global. Mas essas posições, às vezes consideradas mais críticas, encontram-se frequentemente frente a objeções doutrinais ou à exigência de soluções concretas. Sobre o primeiro, é esperável que o conhecimento dominante de DIE embargue visões alternativas à ordem econômica global a partir do pretexto que são políticas e parciais. Não obstante, como fica claro neste trabalho, o mesmo pode ser dito sobre o conhecimento dominante. A respeito dos pedidos de soluções concretas, estes partem de uma aceitação implícita da ordem vigente. Esses pedidos não admitem que uma solução verdadeira pode requerer mudanças nos termos do debate ou na forma de pensar os problemas.

Pensar alternativas, em outras palavras, requer uma atitude ativa frente à criação de conhecimento. Mas a articulação de alternativas concretas, também, enfrenta um forte obstáculo epistemológico. O DIE atual somente pode ser entendido com base em certas premissas neoclássicas, neoliberais e pós-liberais que dão forma à ordem vigente. Por exemplo, a relação entre o investimento estrangeiro e o livre comércio com o desenvolvimento é chave. Esta conexão está sempre presente na racionalidade atual do desenvolvimento. $\mathrm{O}$ DIE podia ter um conteúdo emancipador para o Sul global quando existia uma visão econômica alternativa do comércio e dos investimentos: a teoria da dependência e da integração econômica regional traziam este apoio epistemológico. $\mathrm{Na}$ atualidade, a falta de uma visão econômica alternativa torna difícil para que os acadêmicos do DIE articulem uma visão da ordem econômica vigente onde tenham-se em conta as desigualdades tanto materiais como normativas.

Ao mesmo tempo, também é necessário ter presentes as limitações epistemológicas impostas pelo próprio DIE. Essa área do conhecimento está inevitavelmente ligada à globalização econômica. Para quem a globalização é um problema, então, é provável que uma resposta satisfatória encontre-se em discursos mais radicais que os que se podem articular a partir do DIE. Da mesma forma, certas contribuições - por exemplo a partir da sociologia e antropologia - podem ser muito importantes para repensar o DIE, mas idem devem ser utilizadas com cuidado se o que se tenta é reordenar as atuais relações econômicas internacionais. O risco que se corre é que alguns esforços sejam recebidos como vozes exó- ticas pelos acadêmicos de DIE. ${ }^{82}$ Os investimentos estrangeiros, por exemplo, atuam pelo benefício esperado e não por caridade. Qualquer regulação do investimento estrangeiro deverá ter presente esta premissa, ao menos que seu objetivo seja terminar com o investimento estrangeiro e a globalização. Não cabe iniciar neste artigo um debate sobre a viabilidade destas opções mais radicais, mas simplesmente notar que o DIE pode ser um espaço de oportunidades para quem crê que um dia cada país e região poderá escolher seu destino na globalização econômica.

\section{ReferênCIAS bibLIOGRÁfiCAS}

ABBOTT, Kenneth; SNIDAL, Duncan. Why states act through formal international organizations. Journal of conflict resolution, v. 42, n. 1, 1998.

ANGHIE, Anthony. Imperialism, Sovereignty and the Making of International Law. New York: Cambridge University Press, 2004.

BAADE, Hans. Teaching International Economic Law. Journal of Legal Education, v. 59, 1963.

BECKER LORCA, Arnulf. International Law in Latin America or Latin American International Law-Rise, Fall, and Retrieval of a Tradition of Legal Thinking and Political Imagination. Harvard International Law Journal, v. 283, 2006.

BECKER LORCA, Arnulf. Mestizo International Law: a Global Intellectual History 1842-1933. Cambridge: Cambridge University Press, 2014.

BECKER, Félix. Los Tratados de amistad, comercio y navegación y la integración de los estados independientes americanos en el sistema internacional. In: PROBLEMAS de la formación del Estado y de la nación en Hispanoamérica. 1984.

BEDJAOUI, Mohammed. Towards a new international economic order. New York: Holmes \& Meier, 1979.

BIELSCHOWSKY, Ricardo. Cincuenta años del pensamiento de la CEPAL: una reseña. In: CINCUENTA

82 O trabalho de Boaventura de Souza Santos sobre epistemologias do sul, por exemplo, é uma ferramenta importante para repensar o DIE. Não obstante, pode haver o risco de transformar um discurso alternativo em uma voz exótica. Neste sentido, ver supra n. 52 , p. 166. 
años del pensamiento de la CEPAL: textos selecionados. Santiago: Fondo de Cultura Económica/CEPAL, 1998.

BRAVO, Karen. International Economic Law in US Law Schools: Evaluating its Pedagogy and Identifying Future Challenges. In: COLIN, Picker et al. (Ed.). International Economic Law: the state and future of the discipline. London: Hart Publishing, 2008.

CHANG, Ha-Joon. Regulation of Foreign Investment in Historical Perspective. The European Journal of Development Research, v. 16, n. 3, 2004.

CHANG, Ha-Joon. Kicking away the ladder: development strategy in historical perspective. London: Anthem, 2002.

CHIMNI, Bhupinder. International institutions today: an imperial global state in the making. European Journal of International Law, v. 15, n. 1, 2004.

CORREA, Carlos. Intellectual property rights, the WTO and developing countries: the TRIPS agreement and policy options. New York: Zed books, 2000.

CUADERNO, Miguel. The Anti-Capitalist Attitude. In: Private investment: the key to international industrial development. New York: McGraw Hill, 1958.

ENRÍQUEZ ROSAS, José. Derecho internacional económico: instituciones y críticas contemporâneas. México, Porrúa, 2006.

ESQUIROL, Jorge. Can International Law Help: an Analysis of the Colombian Peace Process. Connecticut Journal of International Law, 2000.

ESQUIROL, Jorge. Legal Latin Americanism. Yale Human Rights \& Development Law Journal, v. 145, 2013.

FERRER, Aldo. La importancia de las ideas propias sobre el desarrollo y la globalización. Revista Problemas del Desarrollo, v. 173, n. 44, 2013.

FOUCAULT, Michel. Technologies of the self. In: RABINOV, P. (Ed.). Ethics: Subjectivity and Truth. New York: The New York Press, 1997.

FOUCAULT, Michel. Security, Territory and Population: lectures at the collège de france 1977-1978. Chippenham, UK: Palgrave Macmillan, 2009.

FOUCAULT, Michel. Society must be defended: lectures at the Collège de France, 1975-76. London: Penguin, 2004.
FOUCAULT, Michel. The Birth of Biopolitics: Lectures at the Collège de France, 1978-1979. Chippenham, UK: Palgrave Macmillan, 2010.

GILPIN, Robert. Global Political Economy: Understanding The International Economic Order. Princeton, N.J.: Princeton University Press, 2001.

GROSS ESPIELL, Héctor. Derecho internacional del desarrollo. In: ESTUDIOS de Derecho Económico II. México: Universidad Autónoma de México, 1980.

KOLSKY LEWIS, Meredith. The Trans-pacific Partnership Agreement and Development. In: VOON, Tania (Ed.). Trade Liberalisation and International Co-operation: A Legal Analysis of the Trans-Pacific Partnership Agreement. Cheltenham, UK: Edward Elgar, 2013.

KOSKENNIEMI, Martti. The Politics of International Law. European Journal of International Law, v. 4, 1990.

KUHN, Thomas. The essential tension: selected studies in scientific tradition and change. Chicago: University of Chicago Press, 1977.

LALL, Sanjaya. Reinventing industrial strategy: the role of government policy in building industrial competitiveness. In: UNITED NATIONS CONFERENCE ON TRADE AND DEVELOPMENT, 28, 2004.

LANG, Andrew. Governing As If: Global Subsidies Regulation and the Benchmark Problem. Current Legal Problems, 2014.

LANG, Andrew. World trade law after neoliberalism: reimagining the global economic order. Oxford: Oxford University Press, 2011.

LISTA, Carlos. La construcción de la conciencia jurídica: los objetivos educativos y la formación del abogado. 5 Anuario-CIJS, v. 381, 1999-2000.

OBREGÓN, Liliana. ¿Para qué un derecho internacional latinoamericano? In: URUEÑA, René (Ed.). Derecho internacional. Poder y límites del derecho en la sociedad global. Bogotá: Uniandes, 2014.

OGLE, Vanessa. State Rights against Private Capital: The "New International Economic Order" and the Struggle over Aid, Trade, and Foreign Investment, 1962-1981. Humanity, v. 211, 2014.

PAHUJA, Sundhya. Decolonising International Law: development, economic growth, and the politics of universality. Cambridge: Cambridge University Press, 2011. 
PAPARINSKIS, Martins. The international minimum standard and fair and equitable treatment. Oxford: Oxford University Press, 2013.

PAULSSON, Jan. Arbitration without privity. ICSID Review, v. 10, n. 2, 1995.

PÉREZ PERDOMO, Rogelio. Desafíos de la educación jurídica latinoamericana en tiempos de globalización. El otro derecho, 2008.

PERRONE, Nicolás. The International Investment Regime and Foreign Investors' Rights: Another View of a Popular Story. 2013. Thesis (PhD) - London School of Economics and Political Science, London, 2013.

PETERSMANN, Ernst-Ulrich. Transformation of the World Trading System through the 1994 Agreement Establishing the World Trade Organization. European Journal of International Law, 1995.

PREBISCH, Raúl. El desarrollo económico de la América Latina y algunos de sus principales problemas. Desarrollo Económico, 1986.

RASULOV, Akbar. The Structure of the International Legal Discourse. In: FLORENCE FOUNDING CONFERENCE. European Society of International Law, 2004.

ROBERTS, Alasdair. The logic of discipline: global capitalism and the architecture of government. New York: Oxford University Press, 2010.

RODRIK, Dani. The Global Governance of Trade: As If Development Really Mattered. United Nations Development Programme Background Paper, 2001.

ROSAT'TI, Horacio. Los tratados bilaterales de inversión: El arbitraje internacional obligatorio y el sistema constitucional argentino. La Ley, v. 67, n. 198, 2003.

RUGGIE, John. What makes the world hang together? Neo-utilitarianism and the social constructivist challenge. International Organizatio, v. 52, n. 4, 1998.

SAGAFI-NEJAD, Tagi; DUNNING, John. The UN and Transnational Corporations: from code of conduct to global compact. Bloomington: Indiana University Press, 2008.
SCHNEIDERMAN, David. Constitutionalizing Economic Globalization. Investment Rules and Democracy's Promise. New York: Cambridge University Press, 2008.

SERRA, Narcís; SPIEGEL, Shari; STIGLITZ, Joseph. Introduction: From the Washington Consensus Towards a New Global Governance. In: THE WASHINGTON Consensus Reconsidered: Towards a New Global Governance. New York : Oxford University Press, 2008.

SHAFFER, Gregory et al. The trials of winning at the WTO: what lies behind Brazil's success. Cornell International Law Journal, v. 41, n. 2, 2008.

SIMPSON, Gerry. On the magic mountain: teaching public international law. European Journal of International Law, v. 10, n. 1, 1999.

SWEDBERG, Richard. Max Weber's Contribution to the Economic Sociology of Law. Annual Review of Law and Social Science, v. 61, 2006.

TREBILCOCK, Michael; HOWSE, Robert. The regulation of international trade. New York: Routledge, 1999.

VAN HARTEN, Gus. Investment treaty arbitration and $p u$ blic law. New York: Oxford University Press, 2007.

WADE, Robert. What strategies are viable for developing countries today? The World Trade Organization and the shrinking of development space. Review of International Political Economy, v. 10, n. 4, 2003.

WEBER, Max. El sentido de la 'neutralidad valorativa' de las ciencias sociológicas y económicas In: ENSAYOS sobre Metodología Sociológica. Buenos Aires: Amorrortu Editores, 1973.

WEBER, Max. Parliament and Government in Germany under a New Political Order. In: LASSMAN, P. (Ed.). Weber: Political Writings. Cambridge: Cambridge University Press, 1994.

ZOELLICK, Robert. Unleashing the trade winds. The Economist, v. 5, dec. 2002. 
Para publicar na Revista de Direito Internacional, acesse o endereço eletrônico www.rdi.uniceub.br ou www.brazilianjournal.org.

Observe as normas de publicação, para facilitar e agilizar o trabalho de edição. 